\title{
JORGE GUILLÉN, LECTOR DE GÓNGORA
}

\author{
Miguel A. OLMOS \\ Université de Rouen / ERIAC \\ miguel.olmos@univ-rouen.fr
}

Resumen: Análisis del trabajo de Guillén sobre Góngora, una lectura histórica a partir de los comentaristas del XVII unida a una interpretación estética en función de la idea de «motivación», condicionada por la dimensión visual de la escritura y la metodología moderna.

Abstract: Guillén's work on Góngora consists of a historical reading based on XVIIth century commentators. It also contains an esthetic interpretation founded on the notion of «motivation» that is shaped by the visual dimension of modern literacy and methodology.

Palabras clave: Literalidad. Motivación. Visualidad. Escritura. Jorge Guillén. Góngora.

Key Words: Literality. Motivation. Visuality. Literacy. Jorge Guillén. Góngora. 
En una entrevista concedida en 1962, Jorge Guillén declaró que si en todo poeta hay un crítico escondido, en su caso el crítico se había sacrificado siempre por el poeta (Couffon, 1962: 29). Ese mismo año se publicaba Lenguaje y poesía: algunos casos españoles, colección de seis breves estudios que recoge las conferencias impartidas por el poeta castellano en la Cátedra «Charles Eliot Norton», de la Universidad de Harvard, durante el curso 1957-1958. Resumen del largo magisterio universitario de Guillén en España y Norteamérica, la selección parece ser el signo principal de esta obra. El poeta se centra en un reducido número de autores y problemas, refundiendo algunos materiales ya publicados y dejando de lado muchos otros tratados en el resto de su obra crítica. En virtud de esta condensación, puede pensarse que Lenguaje y poesía articula una visión íntegra de la historia de la poesía española, en sus principales líneas y posibilidades: de Berceo a Bécquer y a los contemporáneos, pasando por la mejor lírica del Siglo de Oro (Juan de la Cruz, Góngora). Por su elevado propósito, doctamente fundamentado; por una densa escritura de eficaces virtudes literarias, Lenguaje y poesía ha obtenido un reconocimiento indiscutido y puede considerarse una obra modelo. Acaso por estas mismas razones, apenas ha obtenido, con excepciones contadas, atención directa por parte de los estudiosos (Mayhew, 1991). Los mejores trabajos que se han dedicado a la crítica de Guillén son pues caracterizaciones de conjunto (Chiarini, 1975; Rico, 2003: 17-23), o se ocupan de aspectos muy determinados (Sibbald, 1994a; 1994b), en especial las ideas literarias de los artículos periódisticos de los años veinte, por su relación con la composición de las primeras ediciones de Cántico (Lázaro Carreter, 1990: 180-220; Pozuelo Yvancos, 1994; 1995).

Guillén mismo ha descrito las ideas poéticas vigentes durante el período de su formación como escritor en «Lenguaje de poema: una generación», ensayo que cierra Lenguaje y poesía con una evocación del grupo literario de discutido nombre al que se le adscribe. La imagen que allí se da de la poesía de entreguerras coincide en lo fundamental con los rasgos consensuados hoy: literatura entendida como juego creativo, respeto de la tradición yuxtapuesto a un impulso de originalidad o de ruptura, primacía de metáforas e «imágenes», sentimiento que excluye todo exceso de sentimentalismo, influencia fundamentalmente francesa. Otras notas, más particulares, traducen intereses personales del Guillén de 1960, preocupado por la valoración de su obra en un momento en que la poesía que se hace en España parece haber tomado rumbos muy distintos a los de la suya. Se cuestionan o matizan así las notas de intelectualidad, pureza, «deshumanización» o hermetismo que suelen asociarse, aunque siempre de manera discutible, a la lírica de vanguardia 
(Serrano y Salaün, 2002: 250-264). A todo ello contrapone Guillén una muy simple fórmula descriptiva, llamativa por su factura redundante o paradójica: la escritura de los años veinte se define, antes que por cualquier otra cosa, por su designio de ser una «poesía poética»:

Hay que recoger, para evocar la atmósfera de aquellos años, esta voluntad de poesía como creación, de poema como quintaesenciado mundo. [...] Sí había propósitos de rigurosa poesía como creación. ¿Y si el poema fuese todo él poético? Esta ambición flotaba difusa en la brisa de aquellas horas. Era preciso identificar lo más posible poesía y poema. Sería falso imaginarse una doctrina organizada. [...] Por unos o por otros caminos se aspiró al poema que fuese palabra por palabra, imagen a imagen, intensamente poético (1999: 407).

En el texto transcrito, nociones como «creación» o «imagen» apuntan a una bien conocida consigna de la estética vanguardista: la liberación del artista de la obligación de imitar el mundo. El nuevo mundo es el texto mismo, creación o poíesis autónoma, para la cual no puede haber recetas preconocidas o doctrinarias, con la excepción de una exigencia de identificación de poema y poesía. Este ideal apunta a la justificación sin discontinuidades, en el seno de la unidad superior del poema, de todos y cada uno de los elementos que entran en juego en el texto, más allá incluso de su dimensión semántica («palabra por palabra») o retórica («imagen a imagen»). Tal identificación de poema y poesía ha de lograrse «lo más posible»; esto es, Guillén advierte que el propósito de evacuar del poema todo aquello que no resulte poético es, aunque decidido, sólo una aspiración. Se reconoce pues en el poema un espacio reservado para la imitación, para la impureza, para otras funciones no rigurosamente líricas o creativas.

Este límite en las ideas literarias de Guillén es igualmente perceptible en su lectura de la poesía de Góngora, que parte de una noción de texto deudora del desarrollo moderno de las tecnologías de la escritura y de su énfasis en el aspecto literal o visual del lenguaje. Decir que Góngora representó un ejemplo a los ojos de los poetas del simbolismo y de la vanguardia no supone ninguna novedad, y ello a pesar de que las razones efectivas de su recuperación moderna, en ambigua asociación a Mallarmé, a Rubén Darío y a la idea de «poesía pura», continúen envueltas en una gran confusión de interpretaciones (García de la Concha, 2000: 63-69; Etienvre, 2004). Más que reexaminar los elementos de esta discusión, pudiera ser útil indagar en qué medida Góngora aparece a los ojos de los poetas del período también como un escritor distinto, ajeno e inasimilable, cuya «terrible pureza» puede ser al 
tiempo objeto de fascinación y de repulsa, según escribe Guillén en el ensayo que con el título de «Lenguaje poético» le dedica en Lenguaje y poesía (1999: 336).

A este propósito, los trabajos de Guillén sobre Góngora constituyen un campo de trabajo posiblemente más apropiado que las numerosas notas y ensayos debidos a otros poetas del momento (Alonso, 1978). Guillén conoce muy de cerca la poesía gongorina. A ella había dedicado su tesis doctoral, Notas para una edición comentada de Góngora, leída en 1925 e inédita hasta hace poco (2002). Se trata de una presentación de las «obras», el «genio» y el «tema central» del poeta cordobés, seguida de una edición anotada del Polifemo, en que se vuelve a los comentaristas del siglo XVII para la comprensión de las dificultades de la obra. El poeta colabora así con Dámaso Alonso en la recuperación filológica de la obra de Góngora atendiendo a la recepción crítica de su época, línea de investigación fundamental para los estudios gongorinos en nuestro tiempo (Reyes, 1981: 151; Carreira, 1998: 17-45; Blecua, 2002). Muchos de los argumentos de las Notas para una edición... se retoman en «Lenguaje poético: Góngora», no sin ciertas diferencias de formulación — por ejemplo, las analogías con la poesía de Mallarmé-, que algo dejan ver de la evolución intelectual de Guillén a lo largo de los más de treinta años que separan ambos textos. Con todo, destaca en ellos un interés continuo: la atención al problema de la oscuridad, emblemático de la poesía gongorina más allá incluso del ámbito literario español (Steiner, 1980: 17-47; Roses Lozano, 1994: 66-80). Un retrato de Góngora y la reproducción facsímil de un manuscrito de Mallarmé adornaban, en 1975, los muros del cuarto de trabajo del poeta (Guillén, 1980: 16).

Para un defensor del arte técnico, de la creación como luminosa consciencia, el problema de la oscuridad hubo de suponer un desafío intelectual de primer orden. En su obra crítica, la cuestión aparece de manera intermitente, por ejemplo, a propósito de Paul Valéry y de la posibilidad de una poesía temática (1999: 492-498). A explicar y resolver las dificultades de interpretación también se encaminan los ensayos dedicados en Lenguaje y poesía a la lírica «inefable»o «visionaria» de Juan de la Cruz y de Bécquer. La oscuridad de estos poetas, heterogénea, se sitúa en planos de análisis diferentes - expresivo, receptivo- de sus obras y obliga a seguir métodos de explicación diversos (Iser, 2005: 30-41; Olmos, 2008). Las dificultades de interpretación de Góngora poseen, por su parte, un carácter específico, ligado a cierta vocación enigmática que es una constante de la actividad poética. Pero para la explicación de la textura de la poesía gongorina, además de a las notas de sus comentaristas antiguos, Guillén recurre a un método interpreta- 
tivo diferente. Esta doble vía de acercamiento es indicada ya en la introducción metodológica de las Notas para una edición... A la transcripción selectiva de los comentaristas del XVII, Guillén dice añadir una serie de notas personales con el objeto de acercar la obra de Góngora «a la Poesía de hoy», considerada en «sus aspectos propiamente poéticos» (2002: 22-3):

El nuevo comentarista de Góngora deberá ante todo colegir, compulsar y expurgar los comentarios antiguos, que tanto ayudan a la inteligencia de los textos. Si desatienden la interpretación estética, persiguen el sentido estricto. No se agota un verso preguntándose sólo qué quiere decir. Este problema parcial lo resuelven los comentaristas del XVII con feliz precisión en muchos casos. Sus discrepancias y sus errores importa recogerlos también para rehacer un ambiente, capital en la historia gongorina. [...] Sería enojoso reeditarlos; necesitan de una metódica selección. A veces escriben deliciosamente. Otras arrastran una balumba de humanismo tan docto como farragoso (2002: 21).

Hay pues una doble dimensión en la «inteligencia de los textos»: el «sentido estricto» elucidado por los comentaristas, necesario punto de partida, no basta en sí mismo, sino que se convierte en resorte de una nueva e indeterminada «interpretación estética», poética, actual. Para intentar poner en claro las convergencias y divergencias entre estos dos modos de explotación de la poesía de Góngora será conveniente exponer antes el concepto que de ella se hace Guillén en su ensayo de 1962. «Lenguaje poético» continúa siendo una excelente introducción a los problemas, no pocos, de la obra de Góngora, desde la índole de sus relaciones con la tradición, hasta sus modulaciones genéricas y cronológicas, pasando por su revolucionario planteamiento retórico o su debatido lugar en la poesía contemporánea. Sólo por una síntesis ágil y eficaz de estas cuestiones —objeto de mil pesquisas previas que Guillén, aunque se reduzca a citar como autoridad casi única a Dámaso Alonso, está lejos de ignorar- el ensayo de Lenguaje y poesía sobre Góngora puede seguir leyéndose hoy como un trabajo magistral ${ }^{1}$. Por estar referido a una obra de la magnitud de la de Góngora, poseedora en sí misma de una larga y enredada historia crítica, nuestra exposición del trabajo de 1962 será muy esquemática. Nos centraremos para nuestra síntesis en tres puntos clave de la lectura de Guillén, que intentaremos comentar después.

${ }^{1}$ Bajo la referencia «Góngora», el Catálogo de la Biblioteca Jorge Guillén (1996) menciona 75 títulos. 


\section{MATERIA, ARTES, MÉTODO}

El punto de partida de Guillén no es otro que el problema gongorino por excelencia, la oscuridad. Del hermetismo tan debatido por los estudiosos de Góngora se da en este ensayo una definición metódica y precisa: la «rigurosa» poesía del Polifemo y de las Soledades es, según Guillén, «un lenguaje construido como un objeto enigmático» (1999: 310); una «realidad segunda, que se muestra y no se muestra», en la que «lo gongorino se identifica a lo jeroglífico» (1999: 325).

La causa primaria de la oscuridad de Góngora se localiza, como era previsible, en la omnipresencia de la significación indirecta, una de las raíces más profundas de toda actividad poética (N. Frye, 1990: 71-128): metáforas, alusiones, perífrasis. Pero en la definición de Guillén, como en una doble hipálage gongorina, objetos y lenguaje parecen haber intercambiado sus cualidades, confundiéndose. Son los objetos, no las palabras, lo que se construye; mientras que es de las palabras, y no en principio de los objetos, de donde emanan resonancias enigmáticas. El intercambio de atributos entre las palabras y las cosas apunta ya a la presentación de la poesía de Góngora en función de una concepción materializada del lenguaje. Sólo después de haber pasado por un proceso de corporeización, en el que deviene visible - y aun tangible - alcanza el lenguaje una dimensión enigmática, espiritual. Recuérdese por otra parte que es típico de la obra poética de Guillén la presentación de lo espiritual a través precisamente de los cuerpos, de la materia (Macrì, 1976: 31-47; Salaün, 1988).

La idea de un lenguaje convertido en objeto ordena pues en Guillén la descripción de la temática, el estilo y la textura de la poesía gongorina. El inmenso y macizo Polifemo, «héroe cuantitativo» (2002: 221), será su mejor símbolo. Consiguientemente, el tema central de las Soledades no es otro que la Naturaleza, un mundo compacto y consistente donde hasta la luz se solidifica, deviene «dura», puede «pisarse»; donde el hueco o ausencia de la muerte adquiere la corporeidad de sus graves representaciones en sepulcros o túmulos (1999: 316-317), y acciones o movimientos se detienen, prisioneros de sus nombres, en «sustantivos volúmenes de reposo» (1999: 320). En la poesía de Góngora, concluye Guillén, «habrá siempre muchas más cosas —ideas de cosas— que ideas abstractas» $(1999: 323)^{2}$.

2 Estas observaciones provienen de las Notas para una edición..., donde reciben tratamiento más extenso (2002: 221-226). 
Consecuencia notable de tal descripción materialista de la poesía de Góngora será el realce de sus valores sensoriales — visuales y táctiles-, para lo cual, ya desde las Notas... de 1925, Guillén recurre al expediente de compararla con artes no verbales, como la pintura o la arquitectura. En lo que respecta a la primera: la visualidad que emana del Polifemo o de las Soledades no proviene sólo de la abundancia de tropos, figuras o imágenes, sino del uso de técnicas compositivas «pictóricas». Un color puede en ella desplegar todos sus matices: por ejemplo, el gris, de la plata a la ceniza, en la estrofa cuarta del Polifemo; o la escala completa de los blancos —una «gama fría», escribe Guillén-, en la estrofa 28 del mismo poema:

La ninfa, pues, la sonorosa plata
bullir sintió del arroyuelo apenas,
cuando —a los verdes márgenes ingrata-
seguir se hizo de sus azucenas.
Huyera... mas tan frío se desata
un temor perezoso por sus venas,
que a la precisa fuga, al presto vuelo,
grillos de nieve fue, plumas de hielo ${ }^{3}$.

La descripción elemental de la técnica compositiva de Góngora abunda en imagénes tomadas de otro arte, el de la arquitectura, que profundiza la visualidad propia de las artes plásticas redoblándola mediante una sugestión táctil. La asociación de la poesía con la arquitectura, menos tópica tal vez que la que la une a pintura, no es menos antigua (Devoto, 1972). Según Guillén, la poesía de Góngora es eminentemente arquitectónica en tanto que su textura es fruto de razones, de simetrías, de órdenes y proporciones. Góngora es el mejor «poeta-arquitecto»; sus obras, impecables «edificios de palabras», erigidos en «tensión máxima» (1999: 312-313). Las imágenes y metáforas que en ellos se entretejen no son ornatos superficiales, sino materia constructiva: «mármol» poemático (1999: 323).

Una implicación fundamental del uso de símiles pictóricos y arquitectónicos — así como de otros, como veremos, tomados de la escultura — para la descripción de la poesía gongorina es sin duda la defensa por parte de Guillén del principio de «arte» como factor crucial en la obra poética. Se trata de un reclamo constante en la labor crítica de un escritor famoso por su con-

3 «La gama fría asocia ahí lo material y lo espiritual: «plata», «azucenas», «frío», «temor perezoso», «nieve», «plumas», «hielo». Todo es blanco junto a una vibración verde: «los verdes márgenes» «(1999: 323-324). La observación se encuentra ya en las Notas... (2002: 139). 
cepción técnica y consciente de la creación literaria (Lledó, 1995). A ella se someten incluso las producciones caracterizadas por una impulsión irracional o instintiva, como la poesía del surrealismo (1999: 511-514). Ésta es también su posición en lo que se refiere al «método» gongorino, fundamentado, escribe Guillén, en razones, en el hallazgo de una ordenación intelectual y sensorial entre los elementos (1999: 319). Las relaciones así halladas reúnen objetos remotos entre sí, o fabrican entes compuestos y sorprendentes: Galatea junto a un arroyo deviene así para el pastor Acis doble «cristal», sonoro y silente, uno para ser contemplado, otro para ser bebido. Las ideas se despliegan pues en comparaciones, en contrastes o en antítesis; explotan unas correspondencias que, además, se expresan geométricamente, trazando paralelismos: «Todo es par, equivalente o contradictorio» (1999: 314). Escribe Guillén:

es la inteligencia con los sentidos quien tiende una red de relaciones entre los objetos. Relaciones de carácter muy racional entre los objetos sensibles: ahí está el quid de la poesía gongorina. [...] Ninguna «impresión» ha originado esa metáfora. Las afinidades [...] han sido descubiertas por los ojos y la razón o, más bien, por los ojos de la razón. [...] De esta suerte ponen las imágenes en contacto objetos muy remotos entre sí. La inteligencia abarca más que las impresiones y las emociones, de raíz más reducidamente personal. [...] La finura de los sentidos funciona con la finura de la inteligencia. Lo abstracto y lo concreto viven contiguos o fundidos, compensándose lo uno con lo otro (1999: 318-319).

Guillén está pensando sin duda en la poética conceptista del siglo XVII, clave fundamental para la comprensión de Góngora en la crítica contemporánea (Carreira, 1986: 25-66; Blanco, 1992: 245-314). A la teoría del concetto hace el poeta alusión con frecuencia en las Notas para una edición... de 1925, en ocasiones con algo de desvío (2002: 82, 120, 132-134). En realidad, agudeza y conceptismo parecen ser uno de los aspectos en que se manifiesta cierta distancia, difícil de franquear, entre la poesía gongorina y la manera en que Guillén está dispuesto a interpretarla.

\section{LOS TIGRES DE SICILIA}

El arte razonable y simétrico que Guillén aprecia en la poesía gongorina, ¿de qué modo se distingue del que anotaron los comentaristas del XVII? ¿A cuáles de las relaciones que mantienen entre sí los elementos que componen el texto poético se aplica? En sus ensayos sobre Góngora, Guillén no explo- 
ra de manera integral todo lo que implican estas cuestiones. Su concepción «arquitectónica» de la obra poética, sometida a «razones», se refiere de manera privilegiada a algunas, muy determinadas. La alusión erudita, corriente en Góngora, es buen campo para la exploración de este problema, que conduce a apreciar relevantes diferencias entre la economía literaria y cultural del siglo XVII y la de nuestro tiempo.

Según Guillén, que sigue una antigua teoría sobre la metáfora y el enigma, el placer poético proviene de una operación de desciframiento, de la tensión experimentada al perseguir el sentido de una formula verbal concreta (Domínguez Caparrós, 1993). En la poesía de Góngora, culmen de la poética humanística, crisol de textos griegos, latinos, italianos y españoles, esta búsqueda es inconcebible fuera del recurso a los materiales literarios heredados (1999: 326). Es esta dependencia de la tradición, insoslayable en el siglo XVII, lo que, según Guillén, exige a Góngora una expresión indirecta, sorprendente, enigmática. La obra poética ha de desarrollar una suerte de jerga lírica, un lenguaje de segundo grado dentro del lenguaje común, un idiolecto construido a partir de usos literarios previos. Por este camino, muy frecuentado por las literaturas occidentales (Curtius, 1984: 384-410), Góngora tiene la bien ganada fama de haber ido más lejos que nadie (1999: 309). Es éste el sentido de la caracterización final de la obra de Góngora como enfática «poesía-poesía» (1999: 336), así como el de la fórmula «Lenguaje poético», aparentemente redundante, con que Guillén había titulado su ensayo.

Las artísticas «razones» de las metáforas y enigmas de Góngora descubren desde esta perspectiva un carácter referencial, que Guillén destaca a propósito de las interpretaciones (los «sentidos estrictos») de los comentaristas del XVII. Lo enigmático puede entonces justificarse exclusivamente por su carácter de referencia a la «verdad histórica», ya sea ésta la de las circunstancias mundanas del poeta y sus lectores, ya la de un saber erudito, que la poesía gongorina reelabora (1999: 327). Guillén transcribe a este respecto varias curiosas anotaciones y algunas enconadas disputas habidas en el siglo XVII sobre la interpretación de lugares concretos de Góngora en función no de lo que hoy llamaríamos resonancias poéticas de las palabras, sino de su sentido referencial. Así, por ejemplo, a propósito de la madera de haya, con que Góngora designa por sinécdoque los navíos, a pesar de que la madera de haya no flota; o de las costumbres deportivas de un determinado halcón africano (el «generoso pájaro» de la estrofa segunda del Polifemo, «generoso» por no cazar sólo movido de la necesidad de alimento, a diferencia de halcones menos preclaros); o bien, por último, a propósito de la clasificación zoológica precisa de unos hipotéticos tigres sicilianos, su piel manchada de 
colores ciento, en la estrofa novena de este mismo poema. En la mente de los literatos del XVII tiene pues gran peso específico el sentido histórico o documental de los elementos de cultura que los géneros poéticos manejan y disponen de manera lúdica, por juego (1999: 326-328). Engañosa o no, la erudición, dependiente de los modos de almacenamiento y recuperación de referencias, es así un factor crucial para la comprensión de la particular factura de la obra poética (Blanco, 1992: 450-453). Ya en la tesis de 1925, Guillén había transcrito las reflexiones de alguno de los comentaristas antiguos sobre los «ojos de lince» que debe tener el «crítico» para advertir, bajo un epíteto cualquiera, la alusión cultural que le da su razón de ser (2002: 134, 170).

Las notas y las discusiones de los comentaristas de Góngora hacen pues patente una economía lingüística específica, una distribución de funciones entre lenguaje, poesía y cultura muy otra que la de nuestro tiempo. Guillén se ocupa de ellas en ocasiones con despego, pero nunca sin atención. Si las reduce a curiosidades, a argumentos secundarios, es en virtud de las características de la economía literaria contemporánea, que le orientan hacia una interpretación en que a los «sentidos estrictos» se superpone con fuerza lo «propiamente poético», una nueva «interpretación estética» que abre un horizonte «infinito» (2002: 116) . Estos aspectos del comentario de Guillén pueden entenderse como plenamente característicos de la poética contemporánea si consideramos que la literatura posterior a 1800, en su acusado interés por lo diferente, lo original, lo extraño, lo subjetivo indefinible, lo «otro», es consecuencia directa del nuevo grado de desarrollo de las tecnologías de la escritura, y de su incidencia en los sistemas modernos de organización, conservación y transmisión del conocimiento (Ong, 1971: 255283). Las razones que se entrecruzan en la textura significativa de la poesía gongorina, las multiformes «correspondencias» intelectuales codificadas en los tratados de Baltasar Gracián, nunca desatendidas, quedan así lejos de la atención inmediata de Guillén, más proclive a otra clase, moderna, de «arte», cuya materia responde igualmente a otros hábitos culturales y literarios.

${ }^{4}$ Escribe Guillén a propósito de una descripción metafórica de Galatea, pavón de Venus es, cisne de Juno: «Caso extraordinario de precisión en la metáfora. La imaginación de Góngora, capaz de tantas empresas, no pierde nunca el tiralíneas. Los parecidos, las comparaciones que Góngora establece, explícanse en el tablero con tiza - y sin mediación de trapo-, porque no hay que borrar nada. En los antiguos comentarios queda desmontada esa Galatea-pavón-cisne. Metáfora domeñable, agotable, muy lejos —en esto- de la poesía moderna, con sus infinitos interiores reservados» (2002: 156; véase también Dehennin, 2004). 


\section{3. «SENTIDO LITERAL LIBRE»}

¿Cómo se orienta Guillén en el laberinto de sentidos — «estrictos» y «estéticos»— de la obra de Góngora? Con prudencia de historiador, atento siempre a excepciones y matices, y contraviniendo su tesis central, Guillén concede que la poesía gongorina no siempre se construye como «poema». Así, puede pensarse en ocasiones que los «dibujos» enigmáticos de las alusiones gongorinas ocultan en realidad sus «objetos», o que el «mármol» poemático degenera en «exceso decorativo» (1999: 331). Se sugiere, de manera complementaria, que ni Góngora ni otros «poetas-poetas» coetáneos percibieron siempre las importantes virtualidades poéticas de la utilización de las palabras cotidianas (1999: 335-336). Se reencuentra pues aquí el desajuste, ya indicado, entre las dos lecturas gongorinas de Guillén. Prima, a pesar de todo, la admiración por la «terrible pureza» de las Soledades y el Polifemo, que, sin embargo, no sólo se explica por una mera recreación lúdica de materiales literarios heredados. Para Guillén, el signo principal de esta «poesía poética» parece ser una adecuación, variamente manifiesta.

Puede aducirse, como primer ejemplo, un pasaje célebre de las Soledades (II, 753-754), un juego de variantes en la caracterización de un ave de presa - esta vez, nórdica: el gerifalte. Este halcón, determinado en una primera redacción del pasaje por una aposición de sentido geográfico (robusto honor del Trión helado), queda calificado en la segunda por medio de una definición laudatoria, vagamente descriptiva: escándalo bizarro / del aire. Escribe Guillén:

A pesar del exceso, en lo más intrincado de aquella selva o, si se prefiere, entre los engranajes de aquella máquina se insinúa ese no sé qué misterioso de toda poesía. Una de las primeras versiones de la Soledad segunda dice:

El gerifalte, del Trión helado

Robusto honor...

Explica Dámaso Alonso: «Los Triones son las estrellas de la Osa Mayor. Aquí, pues, Trión está empleado por Septentrión». O lo que es igual: «El gerifalte, honor del Norte». ¿Por qué, si no por dicha poética, como regalo caído del cielo, se le antojó a don Luis borrar aquellos vocablos y escoger otros muy diferentes que revelaban a esas aves en todo el ímpetu súbito de su vuelo y de su estrépito?

El gerifalte, escándalo bizarro

del aire... 
A ciertos lectores sacude, no hay duda, como una descarga de corriente poética ese impulso que de pronto se impone. ;El gerifalte, escándalo bizarro del aire! También esto es lirismo (1999: 331).

En la reescritura del pasaje, la referencia erudita, que acaso se sienta poco operante, queda desbancada por una expresión de mayor «lirismo», un «no sé qué», estéticamente experimentado. El motivo de la aprobación de Guillén parece ser la «corriente poética»: una mayor eficacia de los factores fónicos y rítmicos de la versión definitiva, en especial por su adecuación a lo significado. El poeta no está solo en esta manera de degustación de la poesía gongorina. Comentando en sus Estudios sobre poesía española contemporánea una metáfora muy similar, Luis Cernuda atestigua una segunda posibilidad de lectura de los versos de Góngora en los círculos literarios del Madrid de 1920, que suma, a su «sentido lógico», un «sentido literal libre» de valor «poético»:

el lector moderno, acostumbrado a las metáforas del creacionismo y del superrealismo, podía desdeñar la explicación lógica de esos versos magníficos [Quejándose venían sobre el guante / Los raudos torbellinos de Noruega, Soledades, II, 972-973] para quedarse con su sentido literal libre de atadura realista, que es donde precisamente reside para nosotros su valor poético. No sé si Góngora y el lector de su tiempo se recreaban ya en la irisación misteriosa de semejantes versos, tomándolos unas veces en un sentido metafórico y otras en un sentido literal; para algunos de nosotros entonces, en los años de la poesía «nueva», el valor de un verso podía consistir en esa doble posibilidad de significado (2002: 187).

No sería imposible rastrear las huellas de una sensibilidad análoga en los detallados análisis estilísticos de Dámaso Alonso en Poesía española, en los que la interpretación estética es una perspectiva importante, pero parcial (1950: 325-418). Por otra parte, tanto Guillén como Cernuda formulan la idea con prudencia. Cabe pues preguntarse cuáles son los resortes que llevan a una percepción «poética» de la literalidad de la poesía de Góngora, y hasta qué punto suponen una novedad propia de su lectura contemporánea.

En el caso concreto de Guillén, semejantes juicios parten de una poética fundamentada en la adecuación recíproca del fondo y de la forma - las «bodas que funden idea y música» con que se distingue el «lenguaje de poema» (1999: 405) —. Se trataría, en esencia, de una tentativa de razonar poéticamente el no sé qué de la poesía, atribuyendo a su experimentación estética, cuyo mejor símbolo es la energía fónica y rítmica del verso, un valor de significación. Por su carácter vago, impreciso, indeterminable, esta significación 
puede designarse como simbólica (Eco, 1990: 229-288). Desde esta perspectiva, el origen de la «adecuación», que tan importantes funciones han desempeñado en la crítica contemporánea, parecería encontrarse en una transferencia impropia del poder rítmico del poema a sus implicaciones de sentido. Esta transferencia sólo es posible por una consideración lenta y minuciosa del texto que es esencialmente gráfica, un escudriñamiento impensable sin una profunda interiorización de la escritura y sus tecnologías, propia del análisis literario contemporáneo (Ong: 1977, 213-230), y todavía no al alcance de los primeros comentaristas de Góngora (Blanco, 1992: 286-289).

Dos tendencias frecuentes en el ensayo de Guillén, la atención específica a la disposición espacial de las palabras en los textos de Góngora, y la intelección del discurso poético a partir del principio de «motivación» de su letra, pueden así comprenderse en función de la incidencia de la visualidad de la escritura en los métodos del análisis de texto.

\section{MELOGRAFÍAS}

La materialidad del mundo poético de Góngora resulta igualmente perceptible en un sentido restringido del que suele hacerse abstracción: el de su representación visual en el espacio gráfico. Los poemas de Góngora pueden así ser edificios, cuadros o estatuas también (o primero) desde una perspectiva estrictamente literal. En otros términos, el soporte material de la representación escrita, sólo manifiesto a los ojos, puede concebirse como elemento significante, creador de un «valor de posición» en los elementos lingüísticos, que se agrega, asincrónicamente, a su comprensión sucesiva en la fluencia del discurso 5 .

Algunos versos de simetría especialmente forzada (Marino, si agradable no, instrumento; Paces no al sueño, tregua sí al reposo) son comentados por Guillén desde esta perspectiva (1999: 313). Claro ejemplo de ello ofrece un hipérbaton más que violento, que Guillén transcribe con una modificación tipográfica que realza un posible sentido icónico latente en el verso (1999: 315):

$$
\text { A las que esta montaña engendra Harpías }
$$

5 «Aunque la poesía sea un arte sucesivo como la música [...], el verso de Góngora suscita sin cesar una metáfora de espacio, y en él se inscribe una entidad, que permanece ante la vista mientras va deslizándose palabra tras palabra ante el oído. Este valor de posición existe siempre en el lenguaje» (1999: 313). 
El verso había sido ya comentado en el mismo sentido en las Notas para una edición..., comparado a la poética visual del Mallarmé de Un coup de dés. En esta obra, un ideal de musicalidad se manifestaba mediante una composición concebida visualmente, como si se tratase de una «partitura» ${ }^{6}$. En el trabajo de 1925, Guillén reducía la observación a una «curiosidad», un «rasgo gracioso» (2002: 233). En el ensayo de 1962, ya sin referencia a Mallarmé, la idea se mantiene en este rango secundario. Sin embargo, Guillén hace notar que, aunque excepcional, estas laboriosas «armonías» pueden naturalizarse, devenir lingüísticas, o, como mínimo, implantar ciertos hábitos en los lectores de Góngora?

¿Cómo se entienden estas «armonías visuales»? En el verso transcrito, así como en otros, Guillén parece seguir los métodos de Dámaso Alonso en Poesía española. El endecasílabo cuanto las cumbres ásperas cabrío, incluido en el Polifemo, había sido allí comentado en función de su disposición gráfica, atribuyendo valor significativo a la posición de las palabras en el espacio del verso. Según Alonso, la violencia del hipérbaton que interpone «las cumbres ásperas» entre la mención de las cabras y su cuantificador remedaría, adecuada y motivadamente, la idea de su salto. En transcripción del crítico:

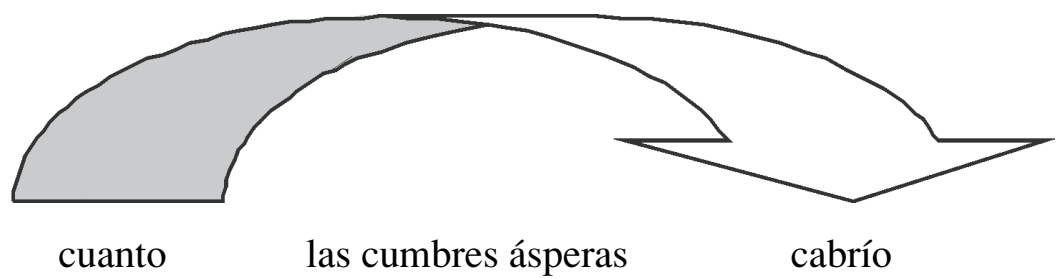

${ }^{6}$ En Un coup de dés «intenta encarnar Mallarmé uno de sus sueños más caros: la poesía considerada cada vez más como una música, y compuesta al fin como una partitura. De ahí, la preponderancia de la página en su totalidad: incorporados los blancos, las palabras, a distancias calculadas y en oportunos caracteres de imprenta, organizan la frase en toda su complejidad de significaciones y sugestiones. [...] El juego se complicaría en otras estrofas, referido a más puntos. Y no sería inútil para la mejor inteligencia de la composición, primordial en la poesía gongorina» (2002: 233-234).

7 Comenta así Guillén el verso transcrito: «Un nivel: los dos cabos del verso en una sola línea recta. Una línea más elevada mantienen los términos intermedios, unidos entre sí y equidistantes: dos cimas en relación con la planicie de los extremos [....]. El oído se acostumbra a estas armonías que, en efecto, sí lo son, acordes a una nueva naturalidad. Naturalidad relativa y por excepción, que no puede prevalecer e incorporarse al futuro de la lengua, sólo sensible a los enriquecimientos de vocabulario, hostil en definitiva a este circo de la sintaxis. Pero Góngora, y sólo él, ha logrado sacar partido artística y poéticamente fecundo de este laborioso forcejeo» (1999: 315). 
Al igual que Guillén, Alonso no atribuye al efecto otro valor que el de una divertida curiosidad. Señala también que la observación se encuentra ya en varios comentaristas del XVII, que la utilizan polémicamente como ejemplo a favor y en contra del gongorismo (1950: 365-369). Se trata pues de un efecto que es inconcebible, ya en su época, sin una introyección profunda de las tecnologías gráficas, que están lentamente transformando la actividad literaria (McKenzie, 1999: 9-30; Chartier, 1996: 17-44), como mínimo en el sentido de favorecer una serie de nuevas posibilidades poéticas (Rodríguez de la Flor, 2003). De hecho, Alonso equipara explícitamente el reconocimiento por los intérpretes del XVII de este tipo de "plasmación intuitiva» a una suerte de «estilística» avant la lettre; aunque el superior grado de implantación de la escritura en períodos posteriores explique que semejantes técnicas interpretativas hayan proliferado sólo mucho después. Y en efecto, estas «armonías visuales», entendidas como transferencia de sentido del medio de representación a lo representado, de la disposición gráfica a los elementos lingüísticos que la constituyen, pueden suponer una sobreinterpretación, una interferencia abusiva de los hábitos visuales de la escritura en la experiencia recta de una obra. Por muy poéticas que parezcan, no todas las relaciones de sentido concebibles han de ser pertinentes o efectivas (Carreira, 1998: 47-73). Así, comentando el análisis de Dámaso Alonso, Rafael Sánchez Ferlosio destaca lo que en él hay de descifrado característicamente profesional, de rebusca intelectualizada de un sentido recóndito en función de relaciones secundarias, no lingüísticas sino visuales, inherentes a la escritura. Según Ferlosio, la percepción de tales «criptogramas»:

es algo que no puede cobrar existencia más que ante la atención descifradora; sin la metódica obstinación de ésta, no habría sido descubierto jamás. El descifrado descubre y constata, en efecto, la abstracta reproducción en las palabras del esquema topológico de la imagen de un movimiento característico del personaje —el cabrío- que semánticamente están representando: el hecho está objetivamente ahí, metido en una página del texto, escondido en el retorcimiento de un hipérbaton - no tan violento, por lo demás, como para exigir, a su vez, un descifrado para la simple toma de sentido, en un oído lo bastante preparado a ello como ha de serlo el de cualquier lector del Polifemo-, pero ¿pinta verdaderamente algo más en el seno del poema que el pasivo ofrecerse a una nada inmediata operación de descifrado? (1982: 242-243).

Sin embargo, la progresiva interiorización de las tecnologías de la escritura ha llevado a sustanciales modificaciones de los hábitos no ya sólo literarios, sino también lingüísticos. Así, la lectura y comentario minuciosos de los textos latinos durante el Renacimiento condujo a una nueva manera de oír 
la poesía de Virgilio, y a la atribución de «cualidades significativas» a la mera presencia de determinadas «letras», origen de una figura retórica de nueva invención llamada a posterior gran éxito, la alliteratio (Vega Ramos, 1992: 38-41). El canal de escritura, cada vez más profundamente interiorizado, favorece así la percepción de nuevas relaciones entre los elementos del texto - relaciones en absoluto limitadas, a pesar de su origen, a los visuales- que demandan a su vez el lanzamiento de un proceso de interpretación que las justifique.

\section{5. «MOTIVACIÓN»Y CRÍTICA}

La existencia de una pluralidad de relaciones entre las dimensiones semántica y acústica de las palabras es fenómeno conocido desde antiguo, que subyace a un viejo debate acerca de la índole natural o convencional del lenguaje. La idea de una motivación recíproca entre sonido y sentido, tópica en poesía, ha tenido un largo desarrollo en muchas escuelas críticas contemporáneas, que la han aplicado igualmente a relaciones entre otro tipo de componentes del poema. En el simbolismo acústico se hace particularmente patente la moderna visión del texto artístico como «sistema de modelización secundario», como un signo comunicativo regido por una reestructuración funcional particular de elementos lingüísticos y culturales heterogéneos (Lotman, 1982). Sin embargo, la busca de motivaciones recíprocas del «fondo» y de la «forma» de una obra en virtud de un examen profundo y minucioso de su texto puede igualmente llevar a confusión, si consideramos que el objeto principal de la crítica no consiste en una manipulación artificiosa de sentidos potenciales, sino en describir las estructuras formales de una obra, tal y como ésta se imprime en la percepción consciente de sus receptores, para mostrar de qué modo ha de tener lugar su lectura recta, su experimentación más intensa y profunda (Martínez Bonati, 1977). Por consiguiente, el método de las «motivaciones», además de poder incurrir en una falsificación histórica, corre el riesgo de conducir a construcciones interpretativas autónomas, más un reflejo del modo de operar de la crítica que una descripción fiel de la obra.

En el ámbito hispánico, el principio de la justificación recíproca de «fondo» $\mathrm{y}$ «forma» obtuvo difusión a partir de los notables trabajos estilísticos de Dámaso Alonso, que parten de divergencias respecto de las ideas de Ferdinand de Saussure en cuanto a la concepción de la arbitrariedad de las relaciones entre las dos caras del signo, significante y significado. Como se 
sabe, Alonso subraya que los significantes no se limitan a transmitir conceptos, sino también matices afectivos, o asociaciones sinestésicas; lo que le lleva a sostener una «vinculación motivada» del signo en poesía (1950: 1929). Los estudios de Alonso sobre Góngora son, como ya se apuntó, fuente principal de inspiración del ensayo de 1962 de Guillén. Se encuentran allí algunas observaciones en que la búsqueda de adecuación entre forma y sentido plantea problemas idénticos a los ya comentados a propósito del pasaje de las cabras de Polifemo. Puede servir de ejemplo el comentario de la escena cinegética que cierra las Soledades (II, 809-823), el retrato de un príncipe a caballo (1999: 328-330):

En sangre claro y en persona augusto,
si en miembros no robusto,
príncipe les sucede, abrevïada
en modestia civil real grandeza.
La espumosa del Betis ligereza
bebió no sólo, mas la desatada
majestad en sus ondas, el luciente
caballo que colérico mordía
el oro que süave lo enfrenaba,
arrogante, y no ya por las que daba
estrellas su cerúlea piel al día,
sino por lo que siente
de esclarecido y aun de soberano
en la rienda que besa la alta mano,
de cetro digna.

Guillén destaca ante todo la cohesión del pasaje, una tirada de versos descriptivos que compone un motivo unitario. Desde la perspectiva de su visualidad, la secuencia puede pues compararse a las producciones de artes no verbales: un «cuadro» o una escultura - una «figura ecuestre», como las de Donatello o Verrocchio (1999: 329) ${ }^{8}$. La composición del fragmento se explica también en función de tensas simetrías arquitectónicas, comparables a «las ventanas de una fachada» (1999: 330): el príncipe parece más grandioso cuanto más modesto, y su caballo es mostrado a la doble luz de un ímpetu colérico y de una sumisión casi cortesana. En sus restantes facetas, el comentario de Guillén sigue las líneas fundamentales de su visión de la poesía de Góngora, ya establecidas: una concepción elemental de la naturaleza (en

8 Algunos textos de Aire nuestro (1968) tratan del mismo tema: «Estatua ecuestre» o «La estatua más ecuestre». 
la sinécdoque que sintetiza el freno del caballo en su materia, el oro), y la transfiguración verbal que embellece con ficciones el mundo hasta conformar una nueva y superior «realidad» (las manchas-estrellas del caballo), indisociable del juego semántico de las palabras.

Resulta con todo especialmente destacable la tendencia de Guillén a considerar la secuencia desde la perspectiva de su «adecuación». La tirada se concibe como un todo sin fisuras, donde el «sentido poético» consiste en la concordancia de los elementos formales con lo que éstos representan. Esta sobredeterminación queda sintetizada en la «armonía» con que «el cuadro [...] casa con el cuento» (1999: 329). Podemos sin embargo preguntarnos hasta qué punto debe racionalizarse esta impresión de armonía en función de alineamientos de sonido y sentido cuya justificación concreta resulta siempre dudosa. Así, algunas observaciones parecen sobre todo «curiosidades», proyecciones artificiosas, pero de rango secundario o inesencial, del descifrado crítico sobre la lectura primera del pasaje (por ejemplo, los efectos de convergencia o de disyunción del «fondo» y de la «forma» en virtud de la licencia métrica de la diéresis, confirmatoria en «Süave», contrastiva en «abrevïando») $)^{9}$. La posición de las palabras en el discurso puede igualmente sobredeterminar su sentido. Según Guillén, «Príncipe» ocupa en el verso 811 una posición adecuadamente primera - subrayada «con su énfasis de esdrújulo»— (1999: 329). También la «arrogancia» del caballo aparece «reforzada» por el inicio de verso, y luego «confirmada» luego por su posición final de cláusula. El método se extiende al dibujo del fraseo: el encabalgamiento prolongado de los versos 813-816 remeda la «fluidez» líquida del río que en él se menciona:

Estos versos de sinuosa curva -que la silva tanto favorece-avanzan a lo largo de repetidos encabalgamientos, por sí transportes de fluidez y velocidad: «ligereza — bebió no sólo...», «la desatada — majestad» $(1999: 329)^{10}$.

Los anotadores del XVII mencionan ya algunas de estas asociaciones de elementos formales y semánticos, en especial las de sonido y sentido, entre otros tipos de correspondencias característicos de la poética conceptista

9 «Así «abrevïada», con una diéresis que no oculta su paradoja: la palabra se estira abrevïando» (1999: 329); «Otra diéresis con radio significativo: «süave», así más suave» (1999: 330).

${ }^{10}$ La observación de Guillén hace pensar en un pasaje de la versión primitiva de las Soledades (la descripción de un río de torcido discurso [...] / en brazos dividido caudalosos / de islas, que paréntesis frondosos / al período son de su corriente) que Dámaso Alonso restituyó a su edición de la obra por juzgarlo rico en «espléndidas imágenes visuales» (Góngora, 1982: 45; 182), y sobre el que se extendieron los comentaristas antiguos (Góngora, 1994: 240-242). 
(Guillén, 2002: 228, 237). Pero los intérpretes antiguos proceden más por acumulación de datos (Mathieu-Castellani, 1990) que mediante análisis sistemáticos de grupos de versos caracterizados por la sobredeterminación. No parece haber en ellos una concepción unitaria de los bloques de discurso de Góngora; sí, en cambio, una curiosa preocupación por la identidad histórica real del príncipe en miembros no robusto mencionado - cuestión de la que sin embargo Guillén se despreocupa, atribuyendo ingeniosamente la primacía del pasaje al artista que lo compuso (1999: 329; Góngora, 1994: 544-546) - En conclusión, cabe preguntarse dónde está el «cuadro» tan admirablemente comentado por Guillén, si en la obra de Góngora, o en su minuciosísimo análisis del poema, dotado hoy de una estabilidad gráfica inimaginable para sus contemporáneos (Carreira, 1998: 75-94; Huysman, 2006). El poeta castellano parece haber vuelto a los anotadores del XVII para recoger de ellos una serie de observaciones y noticias relativas a las tradiciones literarias que encuadran y justifican la obra de Góngora. Muy interesado en ellas, no las retiene, sin embargo, en su totalidad. Por otro lado, su comprensión del poema parece profundamente condicionada por un nuevo concepto de su cohesión textual, de la integralidad de su discurso, tanto en el plano de los temas, como en el de la factura retórica. Desde esta perspectiva, la atención concedida a las diversas «adecuaciones» de la poesía de Góngora parece ante todo la consecuencia de un método de análisis concentrado en sus aspectos unitarios, en los heterogéneos alineamientos que puedan abstraerse en el discurso para consolidar su consonancia, su unidad, acrecentando su sobredeterminación. Esta conceptuación de la poesía parece pues dependiente de la visualidad de la escritura, del canal gráfico en el que naturalmente se desenvuelve para nosotros la percepción del poema (Ong, 1996: 152-164). Se diría en definitiva que los comentarios de Guillén, más aún que como iluminación de la textura del pasaje, convencen por su propio valor, por la nitidez con que generan y traducen los armónicos de una lectura personal del pasaje.

\section{CONCLUSIÓN}

A la percepción por los hablantes de un haz de conexiones entre significantes capaz de generar sentido se refirió de Ferdinand de Saussure mediante la denominación de «motivación relativa» (1967). En virtud de esta noción, algunas corrientes de la Lingüística han puesto en entredicho el «dogma» de la arbitrariedad del signo. Según esta tendencia, los significados no serían «vehiculados» por los significantes; bien al contrario, los signifi- 
cantes tendrían la capacidad de generar por sí mismos (o por acción del hablante) significaciones. La arbitrariedad del signo quedaría así corregida por las relaciones motivadas latentes en el sistema de la lengua. El signo lingüístico estaría motivado porque el lazo entre significante y significado es una relación destinada a la producción de significaciones, de manera particular en toda una gama de actividades lingüísticas — refranes, chistes, juegos de palabras, textos poéticos- menos atendidos que otras producciones, supuestamente más comunes, a las que la Gramática se ha consagrado de manera preferente. La lingüística habría pues quedado concentrada en el estudio del lenguaje en su función de comunicación, descuidando la dinámica generativa de las lenguas, en la que los significantes, lejos de ser vehículos estáticos, «hablan» entre sí en el código de la motivación relativa del sistema (Launay, 2003).

Queda fuera de nuestra competencia entrar en la discusión acerca de la arbitrariedad o la motivación del signo lingüístico, o en la de cuál sea el ámbito de análisis - sistema lingüístico o usos en el hablar efectivo- que le es más propio. Puede sin embargo señalarse que, a imagen de lo que supone en el sistema de la lengua la «motivación relativa» de Saussure, el marco gráfico en que se desenvuelve en la actualidad el análisis literario resulta igualmente proclive a la generación de «significaciones» a partir de la percepción de analogías. Aunque ilimitadamente variadas, este tipo de relaciones de motivación —o imitación — se establece de manera particularmente frecuente y llamativa a partir de los componentes acústicos del lenguaje (Martínez Bonati, 1983: 211-221). Sin embargo, un factor fundamental para la determinación de esta clase de adecuaciones (fonosimbólicas y otras) características de los géneros poéticos parece ser el espacio visual de la escritura, ya desde los tiempos de los primeros comentaristas de Góngora, y de manera aun más acusada en la crítica contemporánea. Al favorecer una consideración atemporal, estática, de la obra poética como unidad o serie de unidades fuertemente cohesionadas, la escritura permite descubrir en el discurso una larga serie de motivaciones o correspondencias, con independencia de que hayan sido efectivas o no en la intención del autor, o en la recepción primera de su obra, corriendo el riesgo de perturbar con ideas preconcebidas el establecimiento de la jerarquía de implicaciones que constituye una interpretación válida (Hirsch, 1967: 94-102). Sintomático de este estado de cosas parece el que algunos interesantes desarrollos de estos métodos hayan tenido lugar en el dominio de la genética textual, esto es, en el seno de una disciplina cuyo objeto no es la obra literaria tal como ha sido dada a su público, sino el conjunto de documentos que permite al estudioso reconstruir imaginativamente 
el proceso íntegro de su elaboración, un «texto» pues plural y movedizo, existente sólo gracias a una elaboración de la crítica, e indisociable de su soporte escrito. Un magnífico ejemplo puede encontrarse, precisamente, en los estudios sobre la genética textual de la poesía de Guillén (Puyau, 2005).

Un problema mayor que plantea a las tareas interpretativas la «motivación» de los textos poéticos es por tanto el de la decisión, propiamente crítica, de su grado de pertinencia, tanto en el plano de la estructura formal de la obra como en el de su comprensión histórica y filológica. Se trata pues de una cuestión general, más allá de la particular lectura de la poesía de Góngora hecha por Guillén. Parece del todo innecesario ponderar la calidad o la coherencia de los estudios elaborados por el poeta castellano; pero es sin duda de justicia agradecerle su brillante y discreta lección sobre cómo ser a la vez fiel al horizonte histórico de la obra y a la sensibilidad estética aprendida en su tiempo. Por último, podría tener interés, en investigaciones futuras, averiguar hasta qué punto los trazos fundamentales de la visión de Góngora en Guillén se filtran en la composición de sus propios poemas. Se sabe por su epistolario que la poesía de Góngora acompañó íntimamente al autor durante largos años, desde los tiempos de los primeros poemas de Cántico (Ciplijauskaité, 1996). No son muchas sin embargo las huellas explícitas de sus largas lecturas en Homenaje, su volumen más explícitamente literario. Sólo tres breves poemas se dedican a Góngora en el epígrafe de la serie «Al margen» que le corresponde, todos ellos marcados por la cotidianidad y el anecdotismo, distantes pues de la rigurosa, hermética escritura del primer Guillén, la mejor valorada ${ }^{11}$. Sin embargo, la deliberada circunstancialidad de estos poemas sueltos, que parece en ocasiones rehuir la poesía (Carnero, 2003: 170), bien pudiera enlazar la actividad creativa de Guillén con aquella dimensión «no poética», contaminada, más cerca de la lengua de todos los días, que acaso se echaba en falta en la «pureza [...] cruel» del lenguaje gongorino (1999: 336). Si fuera verdad que todo poeta lleva en su interior un conjunto de escritores distintos, una relectura de los libros poéticos de madurez de Guillén podría depararnos algunas sorpresas todavía.

11 Por ejemplo, «Intenso octubre», encabezado por el endecasílabo Tenedme, aunque es otoño, ruiseñores: Se ha dorado la fronda, y más aguda / Brilla en su amarillez que en sus verdores / Mientras ya poco a poco se desnuda. / Hay tiempo aún para que te enamores (2003: 50). 


\section{REFERENCIAS BIBLIOGRÁFICAS}

ALONSO, D. (1950). Poesía española. Ensayo de métodos y límites estilísticos. Madrid: Gredos.

- (1978). «Góngora y la literatura contemporánea». En Obras completas, V, 725-770. Madrid: Gredos.

BLANCO, M. (1992). Les Rhétoriques de la Pointe. Baltasar Gracián et le Conceptisme en Europe. Paris: Honoré Champion.

BLECUA, A. (2002). «Apuntes sobre Jorge Guillén y su lectura de Góngora». Voz y Letra XIII. 1, 107-111.

CARNERO, G. (2003). «La poesía integral de Jorge Guillén». En Jorge Guillén. Nuestros premios Cervantes. F. Díaz de Castro (ed.), 162-175. Valladolid: Universidad de Valladolid / Junta de Castilla y León.

CARREIRA, A. (1986). «Introducción». En L. de Góngora, Antología poética (Polifemo, Soledad primera, Fábula de Píramo y Tisbe, y otros poemas), 25-81. Madrid: Castalia.

- (1998). Gongoremas. Barcelona: Península.

Catálogo de la Biblioteca Jorge Guillén (1996). Valladolid: Fundación Jorge Guillén / Junta de Castilla y León / Ayuntamiento de Valladolid / Diputación de Valladolid / Universidad de Valladolid.

CERNUDA, L. (2002). Prosa I. Obra completa, II. D. Harris y L. Maristany (ed.). Madrid: Siruela.

CIPLIJAUSKAITÉ, B. (1996). «Atisbos de Góngora en Cántico». En Guillén at McHill: Essays for a Centenary Celebration, K.M. Sibbald (ed.), 39-55. Ottawa: Dovehouse Editions.

COUFFON, C. (1962). Dos encuentros con Jorge Guillén. Paris: Centre de Recherches de L'Institut d'Études Hispaniques.

CURTIUS, E.R. (1984). Literatura europea y Edad Media latina. Madrid: F.C.E.

CHARTIER, R. (1996). Culture écrite et société. L'ordre des livres (XIV XVIII ${ }^{e}$ siècle). Paris: Albin Michel.

CHIARINI, G. (1975). «La crítica literaria de Jorge Guillén». En Jorge Guillén, B. Ciplijauskaité (ed.), 169-179. Madrid: Taurus. 
DEHENIN, E. (2004). «Góngora y Guillén a la luz de Notas para una edición comentada de Góngora (1925)». En Góngora hoy IV-V. Actas de los foros de debate, J. Roses (ed.), 13-53. Córdoba: Diputación de Córdoba.

DEVOTO, D. (1972). «De Amphion a Eupalinos». Revue de Littérature Comparée XLVI. 3, 415-427.

DOMÍNGUEZ CAPARRÓS, J. (1993). Orígenes del discurso crítico. Teorías antiguas y medievales sobre la interpretación. Madrid: Gredos.

ECO, U. (1990). Semiótica y filosofía del lenguaje. Barcelona: Lumen.

ETIENVRE, J.-P. (2004). «Más allá de Mallarmé: el paradigma gongorino en la Francia del siglo XX». En Góngora hoy $I V-V$. Actas de los foros de debate, J. Roses (ed.), 55-71. Córdoba: Diputación de Córdoba.

FRYE, N. (1990). Anatomy of Criticism. Four Essays. Princeton: Princeton University Press.

GARCÍA DE LA CONCHA, V. (2000). «Introducción». En Poetas del 27. La generación y su entorno. Antología comentada, 21-95. Madrid: Espasa-Calpe.

GÓNGORA, L. (1982). Soledades, D. Alonso (ed.). Madrid: Alianza.

- (1986). Antología poética (Polifemo, Soledad primera, Fábula de Píramo y Tisbe, $y$ otros poemas), A. Carreira (ed.). Madrid: Castalia.

- (1994). Soledades, R. Jammes (ed.). Madrid: Castalia.

GUILLÉN, J. (1968). Aire nuestro. Milano. All'Insegna del Pesce d'Oro.

- (1980). El poeta ante su obra. R. Gibbons, A.L. Geist (eds.). Pamplona: Peralta.

- (1999). Obra en prosa, F.J. Díaz de Castro (ed.). Barcelona: Tusquets / Fundación Jorge Guillén.

- (2002). Notas para una edición comentada de Góngora (1925), A. Piedra, J. Bravo (eds.); J.M. Micó (pról.). Valladolid: Fundación Jorge Guillén / Universidad de Castilla-La Mancha.

- (2003). Homenaje. Reunión de vidas. Madrid: Visor.

HIRSCH, E.D. (1967). Validity in Interpretation. New Haven: Yale University Press. 
HUISMAN, R. (2006). «Las funciones de los signos poéticos en su contexto cultural». Entretextos. Revista electrónica semestral de estudios semióticos de la Cultura 7 , http://www.ugr.es/ maceres/Entretextos/entre7/huisman.htm

ISER, W. (2005). Rutas de la interpretación. México: F.C.E.

LÁZARO CARRETER, F. (1990). De poética y poéticas. Madrid: Cátedra.

LAUNAY, M. (2003). «Notes sur le dogme de l'arbitraire du signe et ses possibles motivations idéologiques». En Mélanges de la Casa de Velázquez 33. 2, 275-284.

LOTMAN, Y.M. (1982). Estructura del texto artístico. Madrid: Istmo.

LLEDÓ, E. (1995). «Consciencia y luz en Jorge Guillén». En Jorge Guillén, el hombre y la obra. Actas del I Simposium Internacional sobre Jorge Guillén, Valladolid, 18-21 de octubre de 1993, A. Piedra y J. Blasco Pascual (eds.), 181-193. Valladolid: Universidad de Valladolid / Fundación Jorge Guillén.

MACRÌ, O. (1976). La obra poética de Jorge Guillén. Barcelona: Ariel.

MARTÍNEZ BONATI, F. (1977). «Lectura y crítica». Revista Canadiense de Estudios Hispánicos I. 2, 209-216.

- (1983). La estructura de la obra literaria. Una investigación de filosofía del lenguaje y estética. Barcelona: Ariel.

MATHIEU-CASTELLANI, G. (1990). «Le commentaire de la poésie (15501630): l'écriture du genre». En Les commentaires et la naissance de la critique littéraire. France / Italie (XIVe-XVI siécles), G. Mathieu-Castellani y M. Plaisance (eds.), 41-50. Paris: Aux Amateurs de Livres.

MAYHEW, J. (1991). «Jorge Guillén and the Insufficiency of Poetic Language». P.M.L.A. 106. 5, 1146-1155.

McKENZIE, D.F. (1999). Bibliography and the Sociology of Texts. Cambridge: Cambridge University Press.

OLMOS, M.A. (2008). «Jorge Guillén y la crítica de la oscuridad. Simbolismo e interpretación en Lenguaje y poesía». Dicenda. Cuadernos de Filoolgía Hispánica 26 (en prensa).

ONG, W.J. (1971). Rhetoric, Romance, and Technology. Studies in the Interaction of Expression and Culture. Ithaca: Cornell University Press. 
- (1977). Interfaces of the Word. Studies in the Evolution of Consciousness and Culture. Ithaca: Cornell University Press.

- (1996). Oralidad y escritura. Tecnologías de la palabra. México: F.C.E.

POZUELO YVANCOS, J.M. (1994). «Poesía y crítica en Jorge Guillén». En La claridad en el aire. Estudios sobre Jorge Guillén, F.J. Díez de Revenga y M. de Paco (eds.), 253-269. Murcia: Caja Murcia.

- (1995). «La poética y la crítica literaria de Jorge Guillén». En Jorge Guillén, el hombre y la obra. Actas del I Simposium Internacional sobre Jorge Guillén, Valladolid, 18-21 de octubre de 1993, A. Piedra y J. Blasco Pascual (eds.), 197-219. Valladolid: Universidad de Valladolid / Fundación Jorge Guillén.

PUYAU, J.-L. (2005). «Motivation relative et signification poétique (à la lumière des avant-textes de Jorge Guillén)». En Actes du Colloque «La parole poétique». Bulletin Hispanique 107. 1, 169-199.

REYES, A. (1981). Cuestiones gongorinas. Obras completas, VII. México: F.C.E.

RICO, F. (2003). Los discursos del gusto. Notas sobre clásicos y contemporáneos. Barcelona: Destino.

RODRÍGUEZ DE LA FLOR, F. (2003). «La lectura gráfica». En Historia de la edición y la lectura en España (1472-1914), V. Infantes, F. Lopez y J.F. Botrel (eds.), 234-244. Madrid: Fundación Germán Sánchez Ruipérez.

ROSES LOZANO, J. (1994). Una poética de la oscuridad. La recepción crítica de las «Soledades» en el siglo XVII. Madrid: Támesis.

SALAÜN, S. (1988). «Jorge Guillén: une conception matérialiste du signe (Cántico)». En Mélanges offerts à Maurice Molho, J.-C. Chevalier y M.-F. Delport (eds.), II, 197-213. Paris: Éditions Hispaniques.

SÁNCHEZ FERLOSIO, R. (1981). Las semanas del jardín. Madrid: Alian$\mathrm{za}$.

SAUSSURE, F. (1967). Curso de lingüística general, A. Alonso (ed.). Buenos Aires: Losada.

SERRANO, C. y SALAÜN, S. (2002). Temps de crise et «années folles»: les années 20 en Espagne (1917-1930). Essai d' histoire culturelle. Paris: Presses de l'Université de Paris-Sorbonne. 
SIBBALD, K.M. (1994a). «Jorge Guillén y las letras inglesas». En Estudios sobre Jorge Guillén, F.J. Díez de Revenga y M. de Paco (eds.), 311329. Murcia: Caja Murcia.

— (1994b). «Kulturkritik: T.S. Eliot, J. Guillén and P. Salinas». En T.S. Eliot and Hispanic Modernity (1924-1993), K.M. Sibbald y H.T. Young (eds.), 47-62. Boulder: Society of Spanish and Spanish-American Studies.

STEINER, G. (1980). On Difficulty and Other Essays. New York: Oxford University Press.

VEGA RAMOS, M. ${ }^{a}$ J. (1992). El secreto artificio. «Qualitas sonorum», maronolatría y tradición pontaniana en la Poética del Renacimiento. Madrid: C.S.I.C. / Universidad de Extremadura. 